\title{
Design Aplikasi Penjualan Tiket Hotel dengan Menggunakan Point of Sales pada Pesona Beach Inn Hotel
}

\author{
Ni Kadek Elisa Trisna Jayanti ${ }^{1}$, I Gede Putu Krisna Juliharta ${ }^{2}$, I Gusti Ayu Agung Istri \\ Sari Dewi ${ }^{3}$ \\ 1,2,3 Program Studi Sistem Informasi Akuntansi, STMIK Primakara, Kota Denpasar, Bali, Indonesia \\ Email: elisatrisna1997@gmail.com
}

\section{Abstract}

This research was conducted to hotel ticket sales application design using point of sales at Pesona Beach Inn Hotel. The data collection technique used in this research is qualitative research methods and descriptive methods, in the form of interviews and direct observation to find out the problems and needs of the hotel. The application design method uses an object based diagram approach with a tools in the form of a Flowchart Data Flow Diagram (DFD) and Entity Relationship Diagram (ERD). Due to hotel operational activities that are still carried out manually so that the services provided by the hotel are not fast enought and the recording is carried out repeatedly causing activities to be ineffective, then created a hotel ticket sales application design using point of sales. The hotel ticket sales application design using point of sales aims to belp reservation activities, record data, calculate cost, and create reports that are still done manually, to be faster and more effective. The hotel ticket sales application design using point of sales at Pesona Beach Inn Hotel uses the PHP programming language with the Code Igniter framework and MYSQL database.
\end{abstract}

Keywords: Hotel, Point of Sales, Code Igniter, PHP

\begin{abstract}
Abstrak
Penelitian ini dilakukan untuk merancang desain aplikasi penjualan tiket hotel dengan menggunakan point of sales pada Pesona Beach Inn Hotel. Teknik pengumpulan data yang digunakan dalam penelitian ini yaitu dengan metode penelitian kualitatif dan metode deskriptif berupa wawancara dan observasi langsung untuk mengetahui permasalahan dan kebutuhan dari pihak hotel. Metode perancangan aplikasinya menggunakan pendekatan diagram berbasis obyek dengan alat bantu berupa Flowchart, Data Flow Diagram (DFD) dan Entity Relationship Diagram (ERD). Dikarenakan kegiatan operasional hotel yang masih dilakukan secara manual sehingga pelayanan yang diberikan pihak hotel menjadi kurang cepat dan pencatatan yang dilakukan berulang kali menyebabkan kegiatan menjadi tidak efektif, maka dari itu dibuatkanlah design aplikasi penjualan tiket hotel dengan menggunakan point of sales. Perancangan design aplikasi penjualan tiket hotel menggunakan point of sales tersebut bertujuan untuk membantu kegiatan reservasi, pencatatan data, perhitungan biaya hingga pembuatan laporan yang masih dilakukan secara manual menjadi lebih cepat dan efektif. Perancangan design aplikasi penjualan tiket hotel dengan menggunakan point of sales pada Pesona Beach Inn Hotel menggunakan bahasa pemrograman PHP dengan framework Code Igniter dan basis data MySQL.
\end{abstract}

Kata Kunci: Hotel, Point of Sales, Code Igniter, PHP

\section{Pendahuluan}

Industri pariwisata merupakan sektor ekonomi terbesar dengan pertumbuhan paling pesat di dunia, khususnya perhotelan. Hotel merupakan suatu organisasi yang bergerak dibidang jasa penyewaan kamar yang terdiri dari beberapa departemen yang memiliki tugas dan tanggung jawabnya masing-masing untuk menjalankan operasional hotel [1]. Pada tahun 2019 Bali berada pada posisi pertama dengan jumlah hotel sebanyak 4.419 hotel [2]. Banyaknya hotel kelas menengah kebawah hingga menengah keatas membuat persaingan semakin ketat terutama bagi hotel yang kegiatannya masih dilakukan secara manual menyebabkan pelayanan yang diberikan kurang cepat. Muhamad Danuri menjelaskan, pentingnya menggunakan sistem yang terkomputerisasi dalam hal 
pencatatan termasuk dalam kegiatan akuntansi yaitu agar dapat mengurangi kesalahan-kesalahan yang terjadi pada proses akuntansi, mempercepat proses pembuatan laporan keuangan perusahaan, serta memudahkan manajemen dalam mengambil keputusan secepat mungkin [3].

Penulis melakukan penelitian ini di Pesona Beach Inn Hotel yang berlokasi di Jalan Poppies I No. 31 Kuta, Bali. Pesona Beach Inn Hotel merupakan salah satu hotel yang segala aktifitasnya masih dilakukan secara manual tanpa bantuan sistem komputer. Berdasarkan dari hasil wawancara terhadap pemilik hotel, selama ini hotel tersebut melakukan kegiatan reservasi, pencatatan data, perhitungan biaya hingga pembuatan laporan yang masih dilakukan secara manual dan kendala yang dialaminya yaitu kurang cepat dan kurang efektif dalam pengerjaannya sehingga pelayanan yang diberikan kepada para tamu menjadi kurang baik. Selain itu penyimpanan data-data dan laporanlaporan yang kurang rapi juga beresiko akan data yang hilang.

Berdasarkan dari kendala yang dihadapi oleh pemilik Pesona Beach Inn Hotel, penulis memberikan solusi dengan merancangkan sistem informasi point of sales (POS) berbasis web. Menurut Silvester Dian Handy, Point of sales merupakan suatu kegiatan yang berorientasi pada penjualan untuk membantu proses transaksi dan mempermudah perusahaan dalam mengelola pelanggannya [4].

Adapun tujuan dari penelitian ini yaitu untuk membantu kegiatan reservasi, pencatatan transaksi hingga laporan agar dapat berjalan dengan cepat dan akurat, serta meminimalisir terjadinya kehilangan data. Penelitian ini dilakukan dengan metode SDLC (System Development Life Cycle) dengan pemodelan $W$ aterfall dan perancangan sistem informasi point of sales tersebut menggunakan bahasa pemrograman PHP dan basis data MySQL.

Pada sistem yang telah dirancang, terdapat tiga entitas yang diperbolehkan mengakses sistem yaitu bagian akuntan yang dipegang langsung oleh pemilik hotel (owner), resepsionis, dan bagian gudang. Sesuai dengan kebutuhan dari hotel tersebut, akuntan hanya bisa menginputkan data user dan data kamar, resepsionis menginputkan data tamu dan data pemesanan yang nantinya akan menjadi data transaksi, lalu bagian gudang hanya bisa menginputkan data barang, baik barang masuk (stock in) maupun barang keluar (stock out) yang akan menghasilkan data persediaan barang. Output yang dihasilkan oleh resepsionis dan bagian gudang akan diproses menjadi laporan dan terkirim ke akuntan, laporan tersebut berupa laporan penjualan dan laporan persediaan barang.

\section{Kerangka Teoritis Dan Pengembangan Hipotesis}

\section{Sistem Informasi Akuntansi}

Menurut James A. Hall, Sistem Informasi Akuntansi (SIA) adalah suatu sistem informasi yang digunakan dalam memproses transaksi keuangan yang dimana terdiri dari tiga subsistem yaitu sistem pemrosesan transaksi, buku besar atau sistem pelaporan keuangan, dan sistem pelaporan manajemen untuk pengambilan keputusan [5].

SIA menurut I Cenik Ardana merupakan suatu sistem yang mengumpulkan, mencatat dan memproses data keuangan dan non keuangan yang terkait dengan transaksi keuangan untuk menghasilkan informasi yang akan digunakan dalam pengambilan keputusan [6]. Definisi sistem informasi akuntansi menurut Deni Alfiansyah adalah proses penyusunan laporan keuangan yang tidak dibuat secara manual melainkan dengan bantuan software (terkomputerisasi) [7]. Berdasarkan definisi tersebut, peneliti mengambil kesimpulan bahwa sistem informasi akuntansi merupakan suatu proses pengumpulan data-data akuntansi menjadi sebuah informasi yang dilakukan secara terkomputerisasi untuk dapat menghasilkan laporan akuntansi yang berguna dalam pengambilan keputusan.

Volume 5 Nomor 2 (2020) Hal. 91-105 


\section{Point of Sales}

Point of Sales (POS) merupakan kegiatan dalam hal proses pencatatan transaksi penjualan hingga pengolahan data guna membantu jalannya operasional suatu usaha dan mempercepat proses penginputan data penjualan. Software dari point of sales sendiri juga dapat diintegrasikan dengan perhitungan akuntansi, dan manajemen barang dan stok. sistem Point of Sales biasanya digunakan di supermarket, restoran, hotel, serta tempat yang membuka jasa retail [8]. Menurut Gilang Pamungkas, point of sales dapat melakukan lebih dari sekedar transaksi jual beli, namun juga berfungsi dalam perhitungan akuntansi, manajemen stok, perhitungan hutang piutang, dan berbagai macam fungsi lainnya [9].

\section{Hypertext Preprocessor (PHP)}

PHP atau Hypertext Preprocessor merupakan bahasa yang berbentuk script yang dimana akan dieksekusi untuk ditransfer dan dapat dibaca oleh client. PHP sendiri didesain untuk pengembangan website dan digunakan sebagai bahasa pemrograman umum [10]. Selain itu definisi PHP pada jurnal yang ditulis oleh Zilzi Zade Tazkia menjelaskan bahwa PHP adalah kepanjangan dari PHP: Hiper Text Processor merupakan bahasa utama script server side yang disisipkan pada HTML yang digunakan untuk membuat aplikasi deskop [11].

Berdasarkan definisi-definisi berikut, maka penulis dapat menyimpulkan bahwa PHP merupakan bahasa pemrograman yang digunakan untuk mengembangkan suatu website yang dimana bahasa tersebut akan dieksekusi dan ditransfer agar dapat dibaca oleh client.

\section{My Structure Query Language (MySQL)}

Basis Data MySQL atau My Structure Query Language merupakan server yang digunakan untuk membuat dan mengolah database, biasanya MySQL dipadukan dengan program PHP dalam menangani permintaan data. Selain itu MySQL juga bersifat gratis sehingga dapat digunakan secara bebas tanpa takut adanya lisensi [12].

\section{Framework Code Igniter (CI)}

Code Igniter (CI) merupakan framework PHP yang bersifat open source yang digunakan dalam membangun website dengan model MVC (Model, View, Controller) agar dapat mempercepat pengembangan aplikasi web. Framework sendiri merupakan kumpulan fungsi, prosedur, dan kelas yang sudah siap digunakan sehingga dapat mempermudah proses pengerjaan suatu sistem. [13].

\section{Metode Penelitian}

Metode merupakan tahapan-tahapan dalam suatu penelitian yang digunakan untuk menyelesaikan suatu masalah. Penelitian menurut Soetrisno Hadi adalah usaha untuk menemukan, mengembangkan serta menguji kebenaran suatu pengetahuan menggunakan metode ilmiah [14].

Metode yang digunakan dalam pencarian data pada penelitian ini yaitu metode penelitian kualitatif dan metode deskriptif. Menurut Irpan Kusyadi, metode penelitian kualitatif merupakan metode dengan melakukan pengamatan terhadap suatu objek penelitian untuk menghasilkan suatu konsep terhadap eksperimen. Sedangkan penelitian deskriptif adalah penelitian yang dilakukan dengan mengumpulkan data dalam suatu penelitian yang akan digunakan sebagai dasar dalam pengambilan keputusan [15].

Metode kualitatif yang dilakukan penulis yaitu berupa wawancara dan observasi untuk mengetahui permasalahan yang dialami oleh pihak hotel dan metode deskriptif berupa pengumpulan data-data yang telah diperoleh untuk mengambil suatu keputusan dalam pembuatan

Volume 5 Nomor 2 (2020) Hal. 91-105 
sistem penjualan tiket hotel dengan menggunakan point of sales serta melakukan studi pustaka untuk mendalami pemahaman mengenai sistem yang akan dirancang.

Unit analisis yang diambil oleh penulis yaitu Pesona Beach Inn Hotel yang beralamat di Jalan Poppies I No. 31 Kuta, Bali. Populasi yang digunakan yaitu laporan penjualan dan persediaan barang tahun 2019. Sampel yang digunakan yaitu buku daftar tamu check in, data pemesanan, nota penjualan, dan catatan persediaan barang dalam gudang. Objek penelitian yang diambil yaitu bagian resepsionis, akuntan, dan bagian gudang pada Pesona Beach Inn Hotel. Berikut ini merupakan gambaran rancangan prosedur penjualan tunai dan pengadaan barang dari hasil wawancara dan observasi yang telah disesuaikan dengan kebutuhan perusahaan yang dimana terdapat tiga entitas yang dapat mengakses sistem point of sales sesuai dengan divisinya:

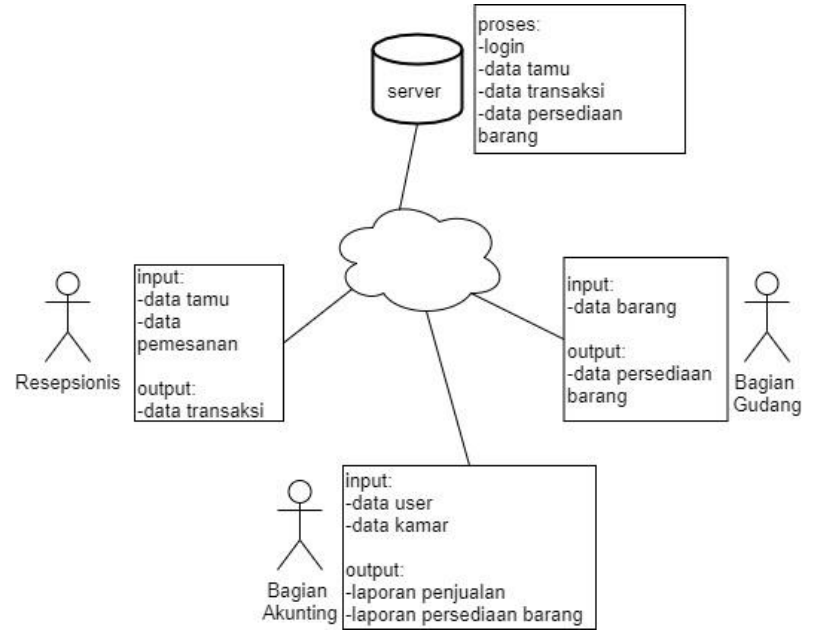

Gambar 1. Rancangan Prosedur Penjualan Tunai dan Pengadaan Barang di Hotel

1. Resepsionis:

a. Melakukan log in dengan memasukkan username dan password untuk dapat mengakses sistem point of sales.

b. Input data tamu dan data pemesanan kamar.

c. Data tamu dan pemesanan akan diproses menjadi data transaksi penjualan dan tersimpan di database.

2. Bagian Gudang:

a. Log in dengan username dan password yang telah dimiliki oleh bagian gudang.

b. Input data barang, data barang masuk dan data barang keluar.

c. Data-data barang tersebut akan diproses dan menghasilkan laporan persediaan barang.

3. Akuntan:

a. Log in dengan username dan password yang telah dimiliki oleh akuntan.

b. Input data user dan data kamar.

c. Laporan penjualan dan laporan persediaan barang yang telah diproses akan terkirim ke bagian akuntan.

\section{Metode Perancangan Sistem}

Metode perancangan sistem yang digunakan pada penelitian ini menggunakan pendekatan diagram berbasis objek dengan alat bantu perancangan aplikasi berupa flowchart atau diagram alir, Data Flow Diagram (DFD) dan Entity Relationship Diagram (ERD). 


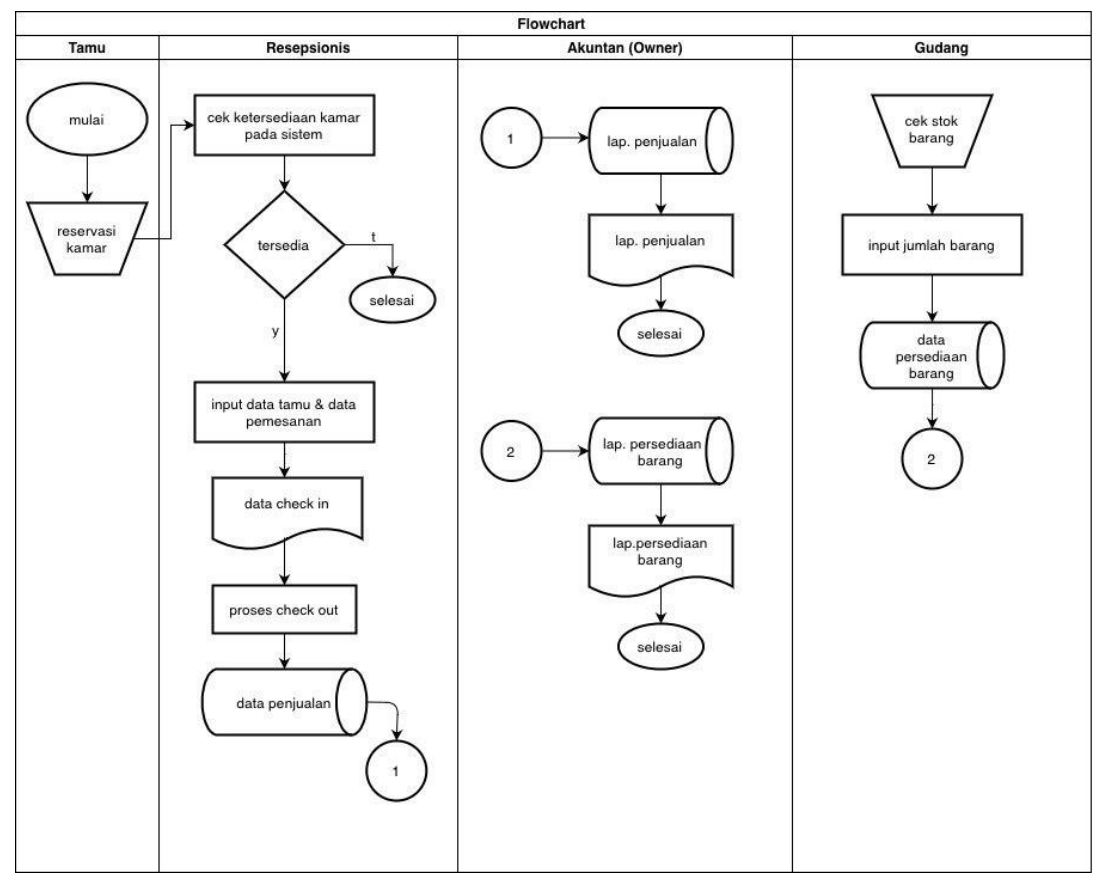

Gambar 2. Diagram Alir atau Flowchart

Pada Gambar 2 Diagram Alir atau Flowchart diatas menjelaskan aliran rancangan usulan sistem pada Pesona Beach Inn Hotel yang akan digunakan dalam pembagian tugas yang dimiliki setiap divisi dalam sistem. Penerapan sistem yang dibangun yaitu dengan menggunakan bahasa pemrograman PHP dengan framework Code Igniter dan basis data MySQL.

Berikut ini merupakan perancangan sistem dengan menggunakan Data Flow Diagram (DFD) Konteks, Data Flow Diagram (DFD) Level 0 dan Data Flow Diagram (DFD) Level 1 serta Entity Relationship Diagram (ERD) yang telah dibuat berdasarkan hasil observasi yang dilakukan sebelumnya agar dapat membantu pembuatan sistem menjadi lebih teratur dan terperinci sesuai dengan kebutuhan yang diinginkan oleh pihak hotel.

\section{Data Flow Diagram (DFD)}

\section{a. DFD Konteks}

Berikut ini merupakan DFD Konteks dari sistem informasi point of sales yang telah diusulkan.

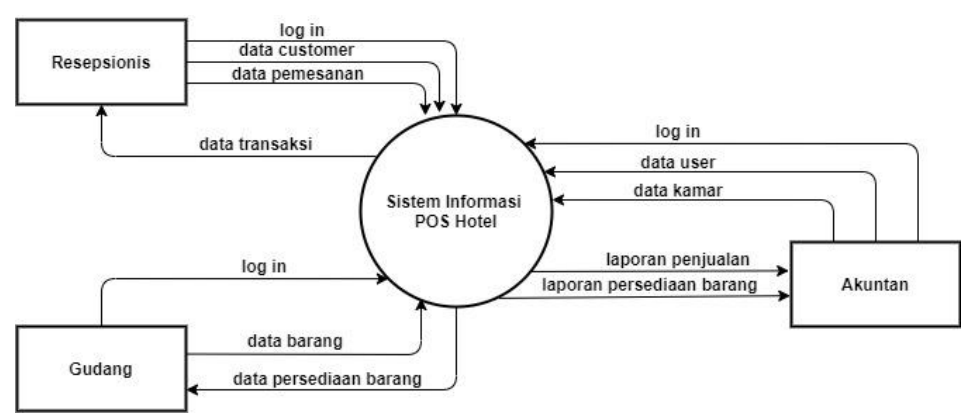

Gambar 3. DFD Konteks 
Ni Kadek Elisa Trisna Jayanti ${ }^{1}$, I Gede Putu Krisna Juliharta 2 , I Gusti Ayu Agung Istri Sari Dewi ${ }^{3}$ @ is The Best: Accounting Information Systems and Information Technology Business Enterprise ISSN: 2252-9853 (Print) | ISSN: 2656-808X (Online)

b. DFD Level 0

Berikut ini merupakan DFD Level 0 dari sistem informasi point of sales yang telah diusulkan.

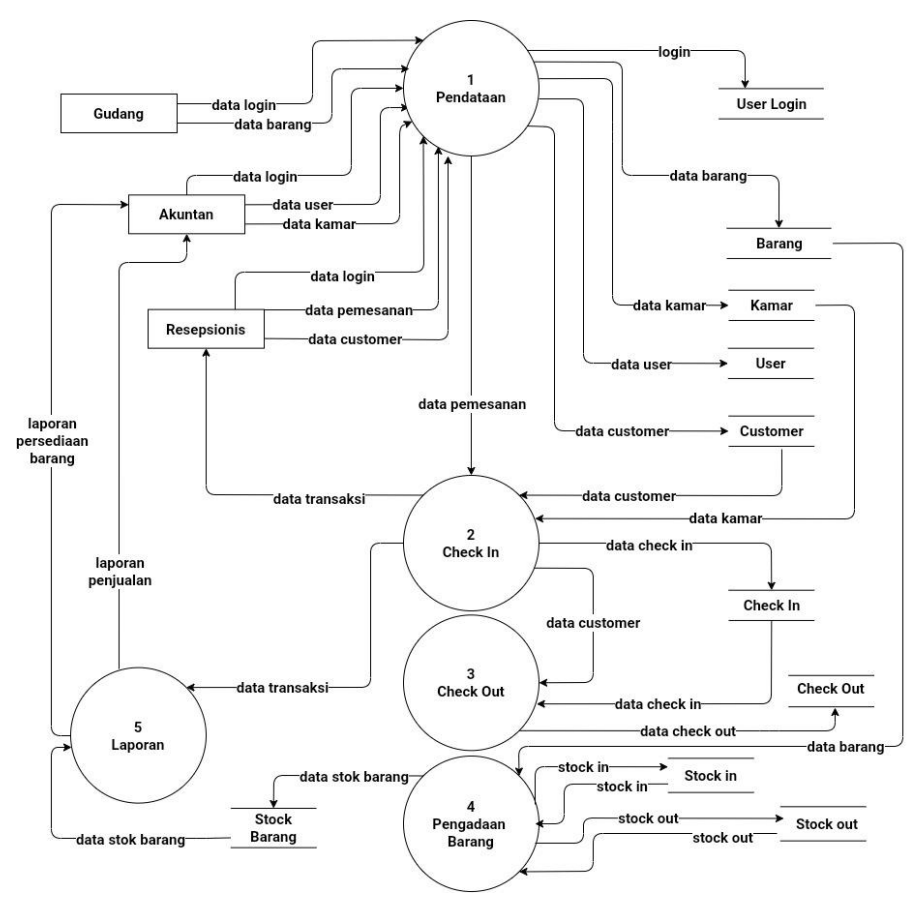

Gambar 4. DFD Level 0

c. DFD Level 1 Proses Pendataan

Berikut ini merupakan DFD Level 1 Proses Pendataan dari sistem informasi point of sales yang telah diusulkan.

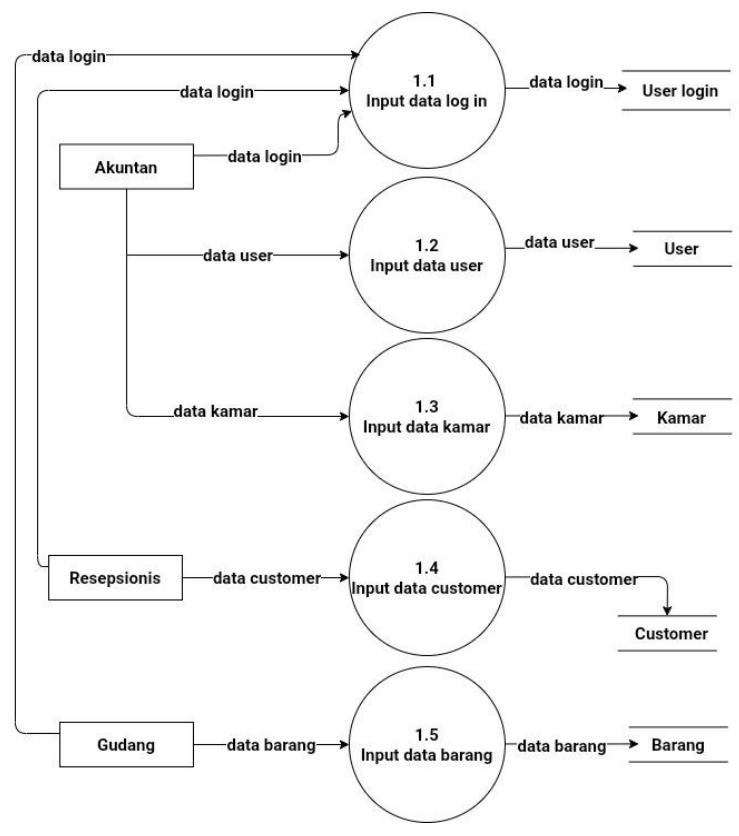

Gambar 5. DFD Level 1 Proses Pendataan 
Ni Kadek Elisa Trisna Jayanti ${ }^{1}$, I Gede Putu Krisna Juliharta 2 , I Gusti Ayu Agung Istri Sari Dewi ${ }^{3}$ @ is The Best: Accounting Information Systems and Information Technology Business Enterprise ISSN: 2252-9853 (Print) | ISSN: 2656-808X (Online)

\section{d. DFD Level 1 Proses Check In}

Berikut ini merupakan DFD Level 1 Proses Check In dari sistem informasi point of sales yang telah diusulkan.

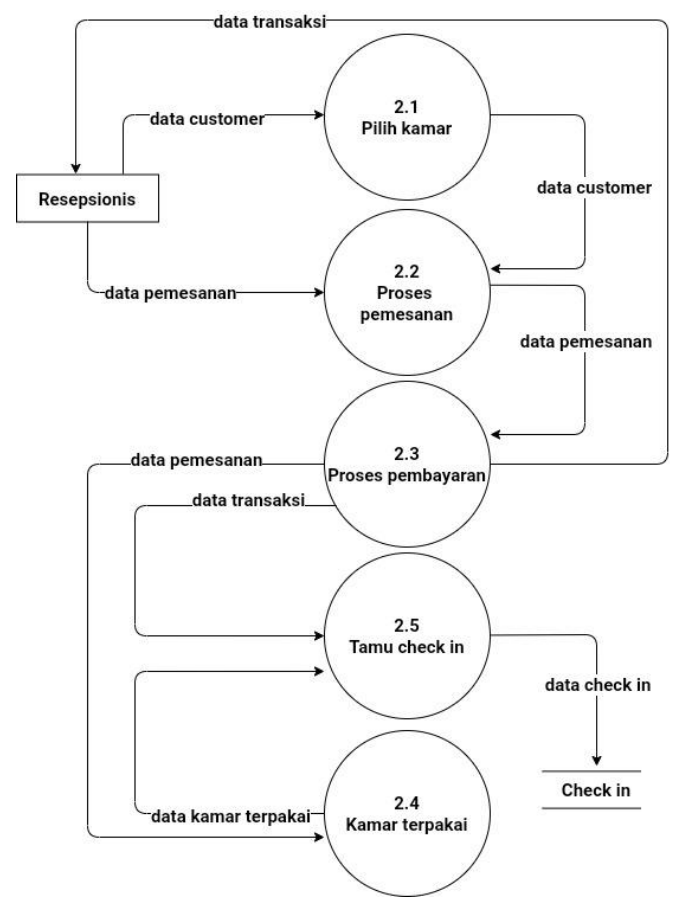

Gambar 6. DFD Level 1 Proses Check In

\section{e. DFD Level 1 Proses Check Out}

Berikut ini merupakan DFD Level 1 Proses Check Out dari sistem informasi point of sales yang telah diusulkan.

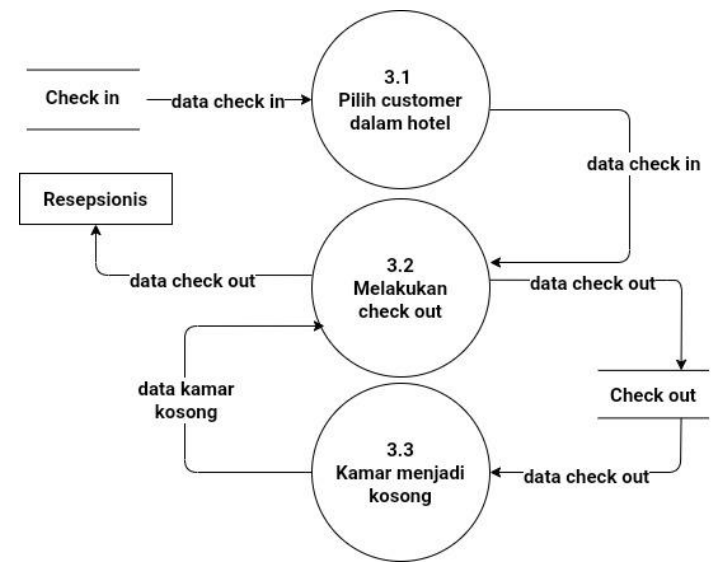

Gambar 7. DFD Level 1 Proses Check Out 
Ni Kadek Elisa Trisna Jayanti ${ }^{1}$, I Gede Putu Krisna Juliharta 2 , I Gusti Ayu Agung Istri Sari Dewi ${ }^{3}$ @ is The Best: Accounting Information Systems and Information Technology Business Enterprise ISSN: 2252-9853 (Print) | ISSN: 2656-808X (Online)

f. DFD Level 1 Proses Pengadaan Barang

Berikut ini merupakan DFD Level 1 Proses Pengadaan Barang dari sistem informasi point of sales yang telah diusulkan

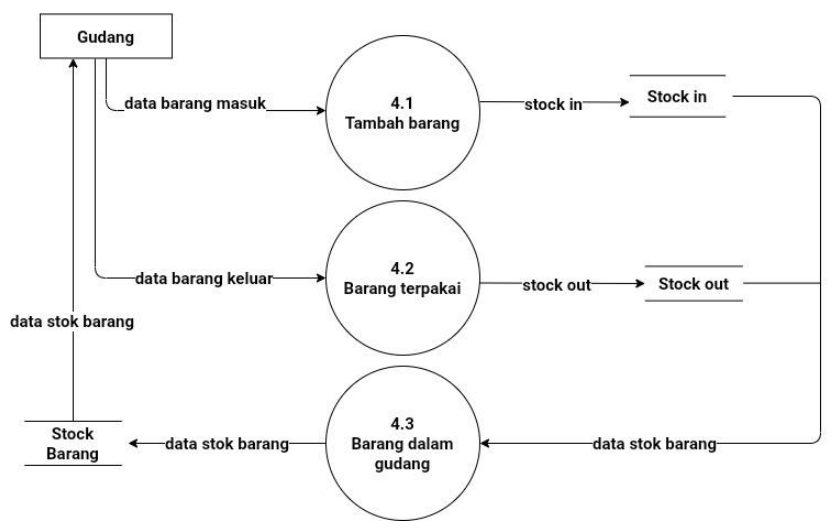

Gambar 8. DFD Level 1 Proses Pengadaan Barang

g. DFD Level 1 Proses Laporan

Berikut ini merupakan DFD Level 1 Proses Laporan dari sistem informasi point of sales yang telah diusulkan.

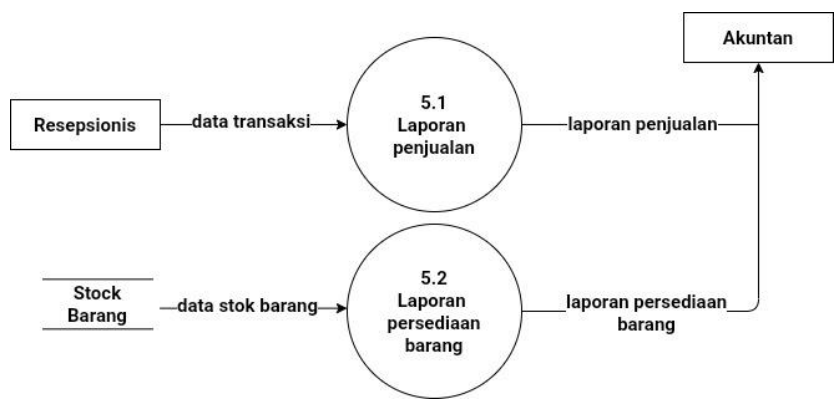

Gambar 9. DFD Level 1 Proses Laporan 
Ni Kadek Elisa Trisna Jayanti ${ }^{1}$, I Gede Putu Krisna Juliharta 2 , I Gusti Ayu Agung Istri Sari Dewi ${ }^{3}$ @ is The Best: Accounting Information Systems and Information Technology Business Enterprise ISSN: 2252-9853 (Print) | ISSN: 2656-808X (Online)

\section{Entity Relationship Diagram (ERD)}

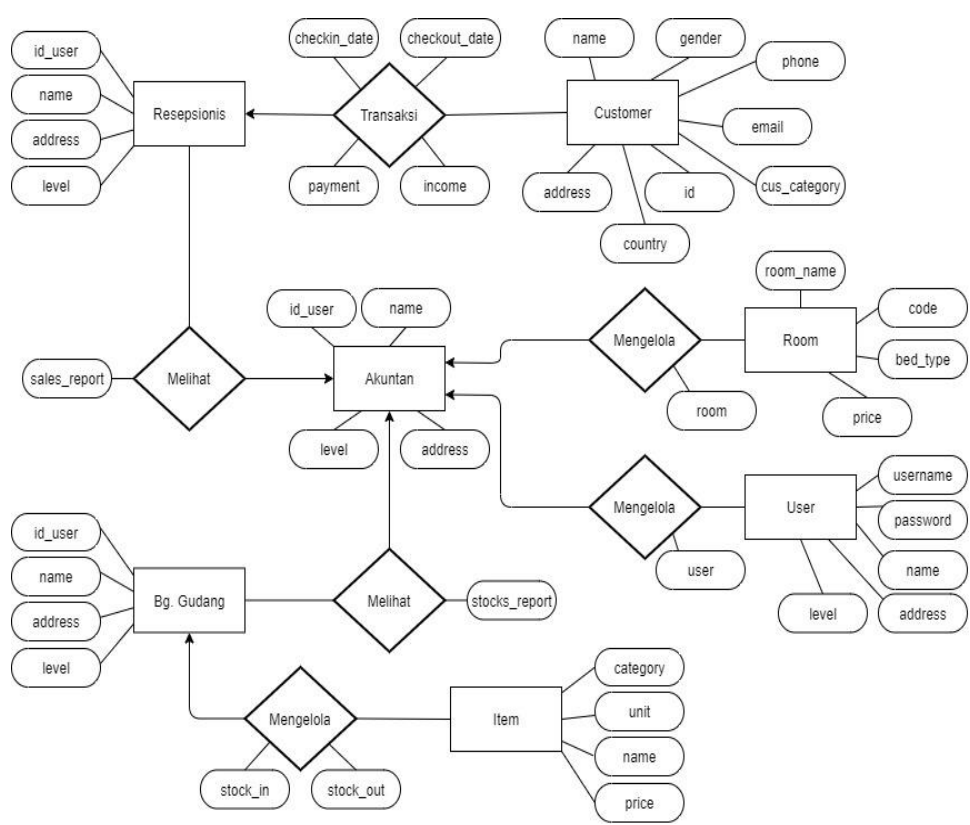

Gambar 10. Entity Relationship Diagram (ERD)

\section{Hasil dan Pembahasan}

Hasil dan pembahasan yang akan dibahas pada penelitian ini yaitu berupa hasil dari perancangan sistem dan pengujian sistem dengan pendekatan black box testing untuk mengetahui apakah sistem dapat berjalan sesuai yang diharapkan atau tidak.

\section{Hasil Perancangan Sistem}

Hasil perancangan sistem yang di desain pada penelitian ini yaitu halaman log in dengan menggunakan akun yang telah dimiliki oleh setiap divisi, halaman customer untuk menambahkan data tamu, halaman check in dan check out yang dikelola oleh resepsionis, halaman stock in dan stock out yang dikelola oleh bagian gudang, serta halaman user dan halaman report dari hasil penjualan dan pengadaan barang yang akan dipegang oleh bagian akuntan.

\section{a. Halaman Log In}

Halaman $\log$ in digunakan untuk dapat mengakses sistem point of sales dengan menginputkan data username dan password yang telah dimiliki oleh setiap divisi, baik bagian akuntan, resepsionis, dan bagian gudang. 
Ni Kadek Elisa Trisna Jayanti ${ }^{1}$, I Gede Putu Krisna Juliharta 2 , I Gusti Ayu Agung Istri Sari Dewi ${ }^{3}$ @ is The Best: Accounting Information Systems and Information Technology Business Enterprise ISSN: 2252-9853 (Print) | ISSN: 2656-808X (Online)

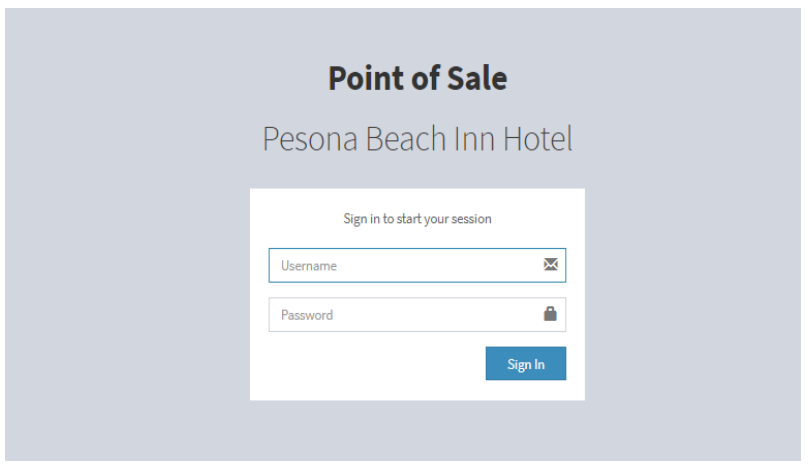

Gambar 11. Halaman Log In

\section{b. Halaman Customers}

Halaman Customers berisikan data-data tamu yang menginap di hotel tersebut. Data-data tersebut dapat dihapus maupun diedit ketika ingin merubah data tamu.

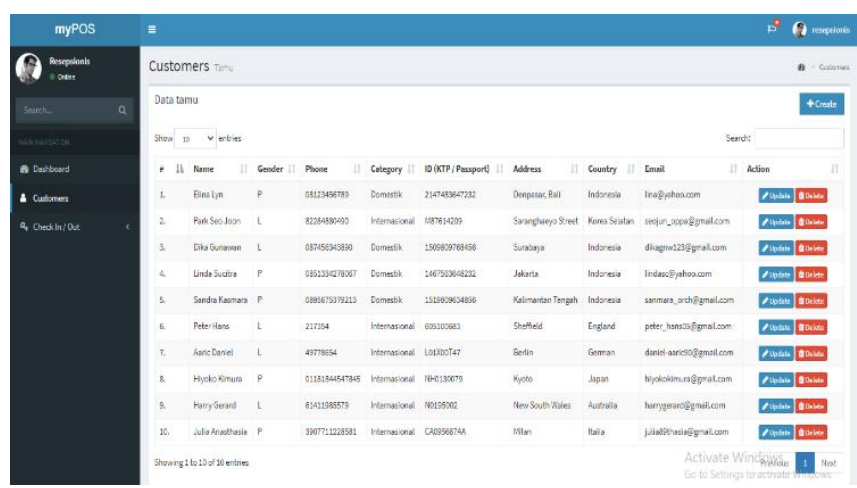

Gambar 12. Halaman Customers

\section{c. Halaman Check In}

Halaman ini berisikan buttons dengan kode kamar, jika terdapat tamu yang ingin melakukan check in maka user perlu memilih button dengan warna hijau yang berarti kamar tersebut tersedia untuk ditempati. Apabila sudah melakukan check in maka button akan berubah warna menjadi merah yang berarti kamar sedang ditempati.

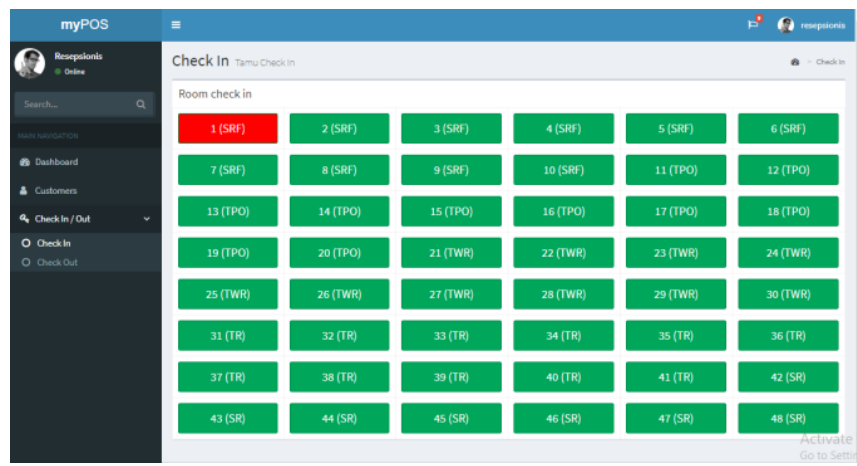

Gambar 13. Halaman Check In 
Ni Kadek Elisa Trisna Jayanti ${ }^{1}$, I Gede Putu Krisna Juliharta 2 , I Gusti Ayu Agung Istri Sari Dewi ${ }^{3}$ @ is The Best: Accounting Information Systems and Information Technology Business Enterprise ISSN: 2252-9853 (Print) | ISSN: 2656-808X (Online)

\section{d. Halaman Check In Form}

Halaman ini digunakan untuk mengisi data tamu yang ingin melakukan check in di Pesona Beach Inn Hotel. Data yang telah terisi akan tersimpan pada database yang telah dibuat dan akan tampil di halaman Check Out.

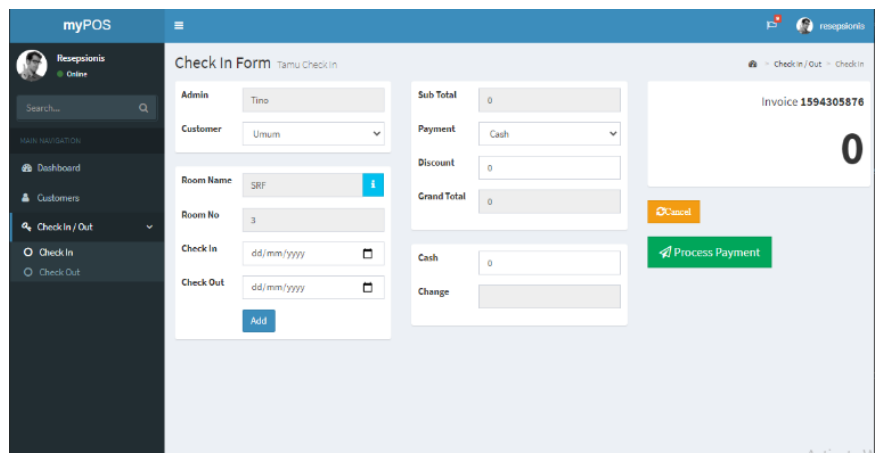

Gambar 14. Halaman Check In Form

\section{e. Halaman Check Out}

Halaman Check Out berisikan data tamu yang telah melakukan check in. Fungsinya halaman ini yaitu untuk membuat halaman nomor kamar yang semula merah karena kamar telah terisi menjadi hijau kembali yang berarti kamar telah kosong dengan men-klik button check out pada kolom action.

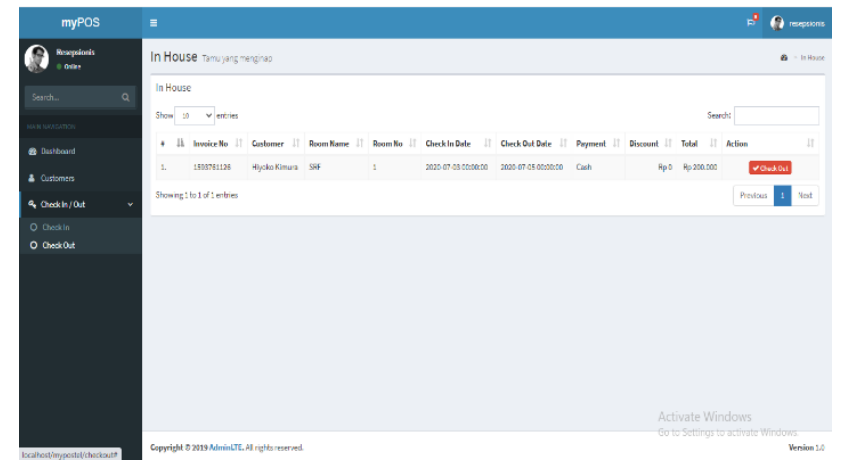

Gambar 15. Halaman Check Out

\section{f. Halaman Stock In}

Halaman ini berisikan data-data barang yang masuk ke gudang, yang dimana pada halaman ini digunakan apabila terdapat penambahan stock barang.

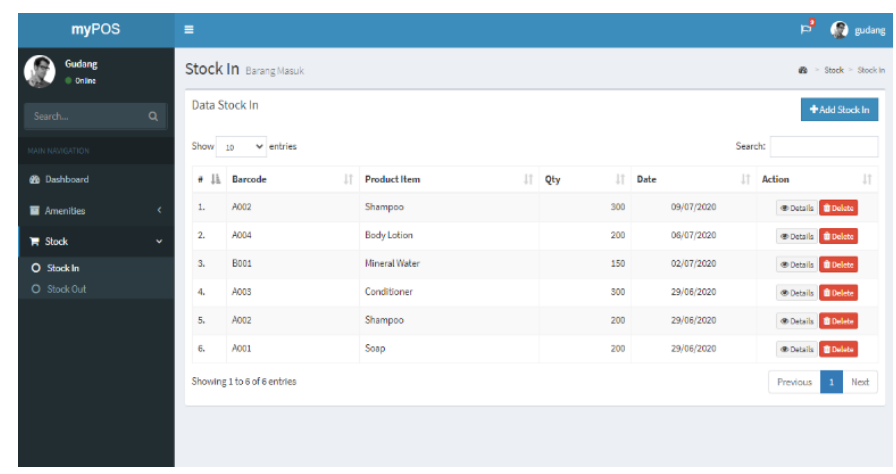

Gambar 16. Halaman Stock In 
Ni Kadek Elisa Trisna Jayanti ${ }^{1}$, I Gede Putu Krisna Juliharta 2 , I Gusti Ayu Agung Istri Sari Dewi ${ }^{3}$ @is The Best: Accounting Information Systems and Information Technology Business Enterprise ISSN: 2252-9853 (Print) | ISSN: 2656-808X (Online)

\section{g. Halaman Stock Out}

Halaman Stock Out hampir sama dengan halaman Stock In, hanya saja inputan pada halaman ini berfungsi untuk menyimpan data barang yang keluar dari gudang. Sehingga ketika mengimputkan data dan jumlah barang pada halaman Stock Out, maka stok akan berkurang secara otomatis pada halaman Items.

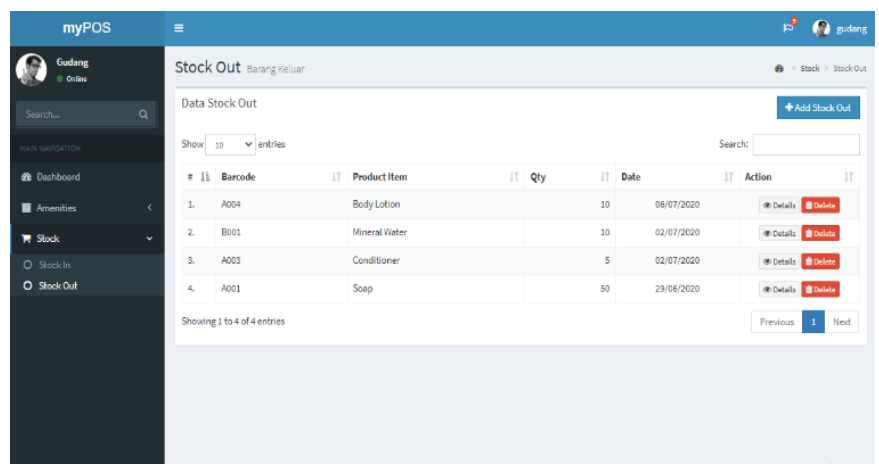

Gambar 17. Halaman Stock Out

\section{h. Halaman Sales Report}

Halaman sales report berisikan data-data penjualan jasa kamar hotel yang dimana data tersebut didapat dari kegiatan reservasi hingga proses tamu melakukan check out. Laporan penjualan tersebut juga dapat dicetak maupun disimpan dalam format PDF.

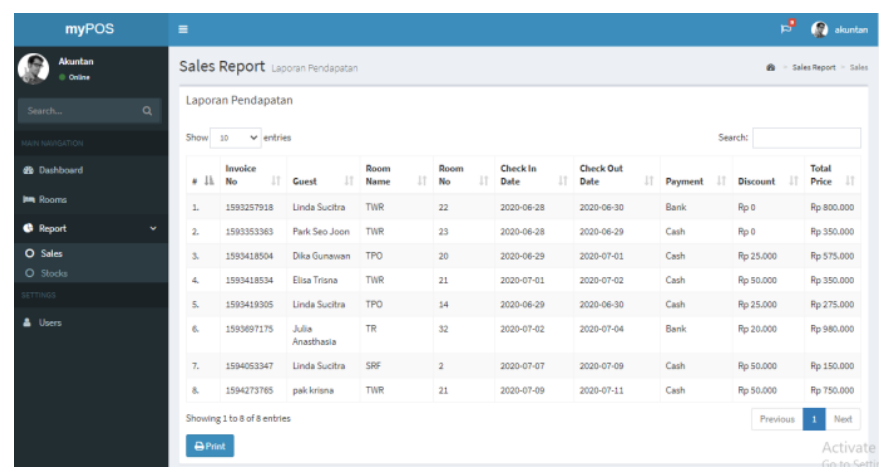

Gambar 18. Halaman Sales Report

\section{i. Halaman Stock Report}

Halaman stock report berisikan laporan persediaan barang dalam gudang, laporan tersebut juga dapat dicetak maupun disimpan dalam bentuk PDF.

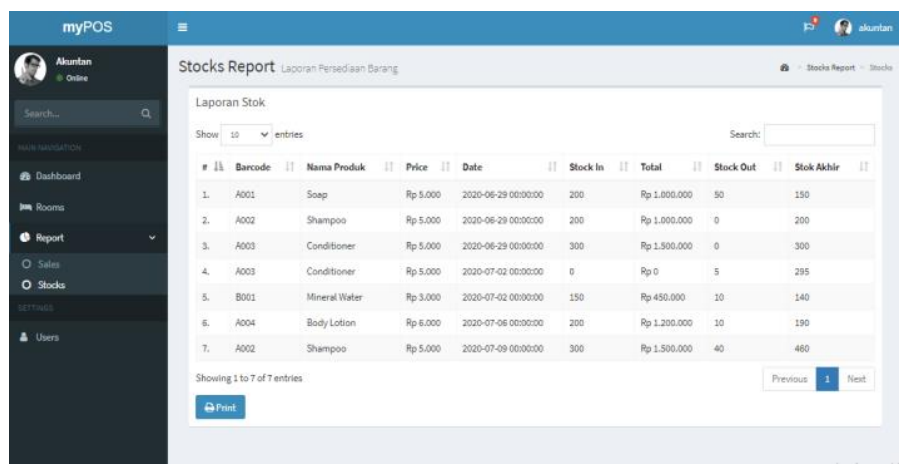

Gambar 19. Halaman Stock Report 
Ni Kadek Elisa Trisna Jayanti ${ }^{1}$, I Gede Putu Krisna Juliharta 2 , I Gusti Ayu Agung Istri Sari Dewi ${ }^{3}$ @ is The Best: Accounting Information Systems and Information Technology Business Enterprise ISSN: 2252-9853 (Print) | ISSN: 2656-808X (Online)

\section{j. Halaman Users}

Halaman Users menampilkan data pengguna yang dapat mengakses sistem, yang dimana hanya pemilik hotel yang bisa mengaksesnya untuk menambah atau mengedit users.

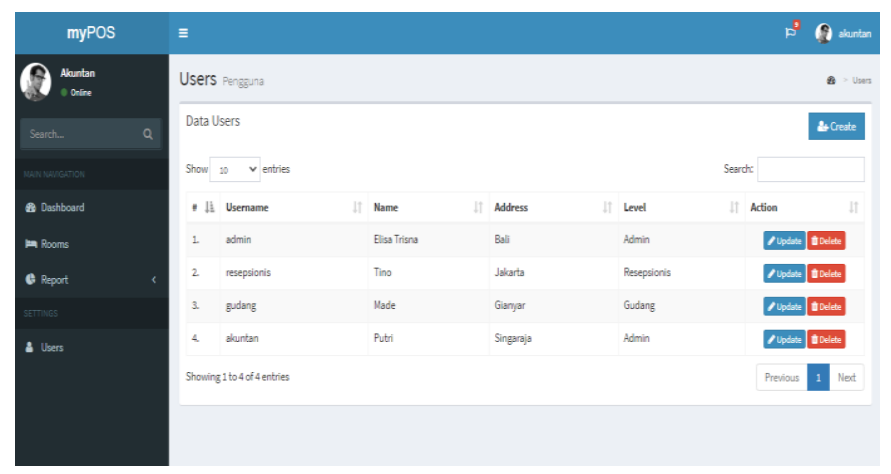

Gambar 20. Halaman Users

\section{Pembahasan}

Hasil dari perancangan Design Aplikasi Penjualan Tiket Hotel dengan Menggunakan Point of Sales pada Pesona Beach Inn Hotel telah dilakukan pengujian sistem dengan pendekatan black box testing, dari hasil pengujian sistem tidak mengalami kendala dan dapat berjalan sesuai dengan yang diharapkan. Berikut ini tabel hasil pengujian yang telah dilakukan:

Tabel 1. Hasil Pengujian dengan Black Box Testing

\begin{tabular}{|c|l|l|l|}
\hline No. & \multicolumn{1}{|c|}{ Rancangan Proses } & \multicolumn{1}{|c|}{ Hasil yang diharapkan } & \multicolumn{1}{|c|}{ Keterangan } \\
\hline 1. & $\begin{array}{l}\text { Klik Menu Log In (yang sudah } \\
\text { diisi username dan password) }\end{array}$ & $\begin{array}{l}\text { Jika inputan salah maka akan } \\
\text { menampilkan peringatan, jika } \\
\text { benar akan masuk ke halaman } \\
\text { utama. }\end{array}$ & Sesuai \\
\hline 2. & Klik Menu Customers & Masuk ke halaman data customers & Sesuai \\
\hline 3. & Klik Add Customer & Masuk ke halaman add customer & Sesuai \\
\hline 4. & Klik Save Customer & Data customer tersimpan & Sesuai \\
\hline 5. & Klik Menu Check In & Masuk ke halaman kode kamar & Sesuai \\
\hline 6. & Klik kode kamar yang dipilih & Masuk ke halaman check in form & Sesuai \\
\hline 7. & Klik Payment & $\begin{array}{l}\text { Data transaksi tersimpan dan kode } \\
\text { kamar yang dipilih berubah } \\
\text { menjadi warna merah }\end{array}$ & Sesuai \\
\hline 8. & Klik Menu Check Out & Masuk ke halaman check out & Sesuai \\
\hline 9. & Klik Check Out & $\begin{array}{l}\text { Kode kamar berubah menjadi } \\
\text { warna hijau kembali }\end{array}$ & Sesuai \\
\hline
\end{tabular}


Ni Kadek Elisa Trisna Jayanti ${ }^{1}$, I Gede Putu Krisna Juliharta 2 , I Gusti Ayu Agung Istri Sari Dewi ${ }^{3}$ @ is The Best: Accounting Information Systems and Information Technology Business Enterprise ISSN: 2252-9853 (Print) | ISSN: 2656-808X (Online)

\begin{tabular}{|c|l|l|l|}
\hline 10. & Klik Menu Stock In & Masuk ke halaman data stock in & Sesuai \\
\hline 11. & Klik Add Stock In & Masuk ke halaman stock in form & Sesuai \\
\hline 12. & Klik Save Stock In & Data stock in tersimpan & Sesuai \\
\hline 13. & Klik Menu Stock Out & Masuk ke halaman data stock out & Sesuai \\
\hline 14. & Klik Add Stock Out & Masuk ke halaman stock out form & Sesuai \\
\hline 15. & Klik Save Stock Out & Data stock out tersimpan & Sesuai \\
\hline 16. & Klik Menu Sales Report & Masuk ke halaman sales report & Sesuai \\
\hline 17. & Klik Print Sales Report & Laporan penjualan dicetak & Sesuai \\
\hline 18. & Klik Menu Stock Out & Masuk ke halaman stock report & Sesuai \\
\hline 19. & Klik Print Stock Out & Laporan persediaan barang dicetak & Sesuai \\
\hline 20. & Klik Menu Users & Masuk ke halaman data users & Sesuai \\
\hline 21. & Klik Add User & Masuk ke halaman add user & Sesuai \\
\hline 22. & Klik Save User & Data user tersimpan & Sesuai \\
\hline
\end{tabular}

Setelah melakukan pengujian dapat diketahui bahwa sistem berjalan sesuai dengan yang telah diharapkan dan dapat membantu kegiatan pencatatan reservasi kamar yang dimana resepsionis hanya perlu memilih kode kamar dan menentukan lama tamu menginap, karena sistem tersebut akan secara otomatis menghitung berapa biaya yang harus dibayar oleh tamu. Pencatatan data persediaan barang pun juga menjadi efektif karena data tersebut akan langsung diproses menjadi laporan yang akan terkirim secara otomatis ke akuntan.

\section{Penutup}

Berdasarkan perancangan dalam Design Aplikasi Penjualan Tiket Hotel dengan Menggunakan Point of Sales pada Pesona Beach Inn Hotel dapat disimpulkan bahwa:

1. Dengan adanya Design Aplikasi Penjualan Tiket Hotel ini dapat membantu pihak hotel dalam meningkatkan pelayanan reservasi kamar pada hotel tersebut.

2. Design Aplikasi Penjualan Tiket Hotel dengan Menggunakan Point of Sales pada Pesona Beach Inn Hotel menyajikan data-data yang terproses menjadi laporan penjualan dan laporan persediaan barang yang akan terkirim secara otomatis ke bagian akuntan (pemilik hotel) untuk dijadikan bahan pertimbangan dalam melakukan perbaikan pelayanan hotel dan meningkatkan efektifitas kinerja di hotel tersebut. 


\section{Daftar Pustaka}

[1] S. M. H. Kustini, General Hotel Management, Yogyakarta: Deepublish CV. Budi Utama, 2017.

[2] B. P. S. Indonesia, Statistik Hotel dan Akomodasi Lainnya di Indonesia 2019, BPS RI, 2019.

[3] M. Danuri, "Solusi Penanganan Akuntansi dengan Komputer," pp. 1-6, 2017.

[4] S. D. Handy, "Analisa dan Perancangan Aplikasi Point of Sale (POS) untuk Mendukung Manajemen Hubungan Pelanggan," Jurnal Teknologi Informasi dan Ilmu Komputer (JTIIK), vol. 2, no. 1, pp. 20-28, 2015.

[5] J. A. Hall, Accounting Information Systems 7E, Yogyakarta: Deepublish CV. Budi Utama, 2017.

[6] I. C. Ardana, Sistem Informasi Akuntansi, Jakarta: Mitra Wacana Media, 2016.

[7] D. Alfiansyah, "Perancangan Sistem Informasi Akuntansi Piutang Usaha Pada Bapel JPKM Surya Sumirat Menggunakan PHP dan MySQL," @is The Best J., vol. 5, no. 1, pp. 1-15, 2020.

[8] S. Hendry, Membangun Aplikasi Point of Sale dengan VB 6.0, MySQL, dan PHP, Jakarta: PT. Elex Media Komputindo, 2010.

[9] G. Pamungkas, "Rancang Bangun Aplikasi Android POS (Point of Sale) Kafe untuk Kasir Portable dan Bluetooth Printer," Mendeley, vol. 6, no. 1, 2017.

[10] P. Andre, PHP Uncover Panduan Belajar PHP untuk Pemula, Duniailkom, 2016.

[11] Z. Z. Tazkia, "Perancangan Sistem Informasi Akuntansi Laporan Keuangan Laba Rugi pada Restoran Eatboss dengan Menggunakan PHP dan MySQL," @is The Best J., vol. 4, no. 1, pp. 426-440, 2019.

[12] B. Nugroho, Aplikasi Pemrograman Web Dinamis dengan PHP dan MySQL, Yogyakarta: Penerbit Gava Media, 2019.

[13] A. H. Ir. Yuniar Supardi, Semua Bisa Menjadi Programmer Codeigniter Basic, Jakarta: PT. Elex Media Komputindo, 2018.

[14] S. S. d. M. A. Sodik, Dasar Metodologi Penelitian, Yogyakarta: Literasi Media Publishing, 2015.

[15] I. Kusyadi, "Penerapan Metode Waterfall untuk Rancang Bangung Sistem Informasi BCF 1.5," Research Gate, 2018. 